\title{
Os caminhos e as linguagens do sertão
}

João Marcelo Ehlert MAIA. Estado, território e imaginação espacial: o caso da Fundação Brasil Central. Rio de Janeiro, FGV, 2012. 224 páginas.

Felipe Maia Guimarães da Silva

A relação entre ideias e política é o fio condutor que orienta o novo livro de João Maia, Estado, território e imaginação espacial: o caso da Fundação Brasil Central. Ao lidar com tema por vezes tão volátil, o autor escolheu um estudo de caso que lhe permite controlar melhor a construção de seu objeto e, a partir daí, montar seu argumento acerca da forma como certa imaginação social sobre o "sertão" brasileiro informou e ajudou a constituir práticas estatais. A Fundação Brasil Central (FBC) foi uma empresa criada nos anos finais do Estado Novo para empreender iniciativas em um território considerado "vasto" e "ignoto", mal delimitado na geografia oficial, mas visto como fonte potencial de riquezas e desenvolvimento. É a partir deste caso que o autor explora as mediações concretas entre as ideias e as políticas que tentaram interpretar e transformar o território brasileiro.

O estudo permite ao mesmo tempo avançar sobre o que o autor gosta de chamar de uma "imaginação espacial”, isto é, as representações do território em um conjunto amplo da produção intelectual, que inclui obras consagradas, mas também outros textos considerados menores, de relatos de viajantes a documentos oficiais. $\mathrm{O}$ cotejamento desta produção textual e a sociologia de seus intelectuais permite desenvolver argumentos que já haviam sido anteriormente levantados pelo próprio autor, desvelando a forma como o vasto espaço dos sertôes ocupou um lugar privilegiado na interpretação do Brasil. Assim, o problema teórico mais geral vincula-se a um interesse específico, qual seja, a relação entre estado e território no longo processo de formação nacional.

O autor é consciente dos riscos de uma sociologia histórica que trabalhe com a "longa duração”, mas reconhece nestas estratégias o mérito de desnaturalizar o tipo atual de estado e mostrar os 
vários caminhos de constituição das redes de poder e autoridade. Contudo, optar exclusivamente pela "longa duração", como nos grandes e clássicos trabalhos de Charles Tilly, Norbert Elias e Michael Mann, poderia dificultar a percepção de dimensões concretas da construção cotidiana do estado. $\mathrm{O}$ risco é mitigado em seu trabalho pela aceitação de uma perspectiva antropológica que enfatiza a necessidade de negociações cotidianas nos processos de imposição da autoridade estatal. Esses processos, por sua vez, requerem recursos práticos e simbólicos, revelando aspectos essencialmente culturais da construção estatal. A "etnografia institucional” permitiria apreender, com base na produção textual dos agentes do estado na FBC, as "linguagens" que revelam formas discursivas pelas quais o estado se constrói e se legitima.

Com efeito, João Maia sugere que essas narrativas são dotadas de um "sentido" que complexifica nossa percepção das tentativas de imposição da autoridade, e que, por sua vez, deixam marcas na história institucional e na cultura política do país. Não é fortuito que o autor inicie e termine seu livro fazendo menção a fatos e problemas do presente, como as greves de trabalhadores em Jirau (RO) e Belo Monte (PA) ou os desafios das novas relações entre o rural e o urbano na periferia de grandes metrópoles latino-americanas, que poderiam ser mais bem compreendidos se desvendadas as linguagens do Brasil Central. Assim, é por meio da cultura e das linguagens que se pode, cautelosamente, especular sobre a "longa duração".

A cultura é elemento decisivo na própria constituição das práticas estatais, como se pode perceber nesta passagem decisiva, retirada de um documento elaborado por João Alberto Lins de Barros, primeiro presidente da $\mathrm{FBC}$ :

[...] o objetivo da Fundação é precisamente integrar na civilização atlântica as regiōes desconhecidas e longínquas, atualmente inaproveitadas, para que o Brasil possa, tomando plena consciência de si mesmo, atingir pelo aproveitamento integral do seu território o lugar que lhe cabe no concerto das grandes potências mundiais (J. A. L. Barros apud Maia, 2012, p. 162).
Essa passagem, de sabor hegeliano, ajuda a compreender o lugar que o sertão ocupava nesta imaginação. Como mostra o livro, o sertão era o "outro" de uma "civilização atlântica" por meio do qual o país poderia "tomar consciência de si mesmo", num movimento que atraía a ação das agências estatais para o interior, conjugando os projetos de modernização com um imaginário de origem romântica. João Alberto, como relata o autor, fora líder tenentista e havia participado da Coluna Prestes, tal como muitos outros políticos e membros da burocracia estadonovista, experiência que parece ter marcado o imaginário de uma geração. Para homens como ele, o Brasil não poderia ser compreendido apenas pelo litoral, mas era no contato com este "outro" Brasil que o país se revelava por inteiro, tanto em sua dimensão simbólica quanto material. Era uma espécie de "habitus tenente" ou de um "saber viajante", não livresco, que exigia o contato com o sertão para que se pudesse conhecer o Brasil e que se tornaria capital acumulado para realizar a interiorização da autoridade estatal.

Este repertório cultural formaria as "linguagens do Brasil Central”, que o autor expõe em quatro capítulos centrais de sua obra. No primeiro, João Maia relata as iniciativas estatais sobre o território durante a primeira República e reconstrói o pensamento social mobilizado por seus intelectuais. $\mathrm{O}$ que vem à tona neste capítulo é o movimento de médicos sanitaristas, o indigenismo da missão Rondon, as iniciativas do Ministério da Agricultura e do Serviço de Povoamento. O quadro ajuda a mostrar os elementos de continuidade entre a Primeira República e a Revolução de 1930, sendo que não se deve pensar que esta última inaugura as intervençôes estatais sobre o território, ainda que tenha produzido um adensamento dos investimentos burocráticos. Assim, ganham sentido iniciativas aparentemente distintas, como a organização do Instituto Nacional de Estatística, depois IBGE, a Divisão de Terras e Colonização, o Conselho de Geografia, a "Marcha para o Oeste", instituiçôes voltadas para conhecer, mapear, racionalizar a população e o território, construindo concretamente as redes de autoridade estatal. A própria FBC é entendida pelo autor neste contexto como um "conjunto específico de 
práticas estatais, com ênfase nos processos de territorialização da autoridade” (p. 26), isto é, a FBC representa mais uma iniciativa para territorializar a autoridade pública.

Além das iniciativas administrativas, outro fio vermelho percorrido pelo autor é o do pensamento social produzido sobre o "Oeste" ou o "sertão" e que se torna estratégico para desvendar o sentido das práticas estatais. Maia percorre os números das revistas Cultura Politica e Novas Diretrizes mostrando a formação de um repertório de ideias sobre o intento de "colonização" do Oeste. Este repertório será adensado no capítulo 3 com o exame de uma produção intelectual mais vasta, composta por relatos de viajantes, textos de geografia e geopolítica, relatos de expediçōes científicas e a literatura de romances e poesias (o "romanceiro" do sertão) publicados ao longo da Primeira República até a década de 1940, incluindo a reedição de obras mais antigas. Deste conjunto o autor destaca três argumentos que serão em seguida trabalhados a partir dos documentos oficiais, mostrando a articulação entre o imaginário e a ação estatal.

Segundo João Maia, o imaginário do sertão consagrava uma estética da aventura; tendia a ver o Brasil Central como uma região de limites indefinidos, de natureza majestosa e ao mesmo tempo de potencial econômico, lugar para a combinação de sentimentos ambíguos de aventura e melancolia, como na antiga tradição dos relatos de viagens. Este espaço ignoto foi enquadrado pelo olhar geopolítico em uma razão abstrata, tipicamente estatal, que procurava racionalizar e dirigir uma história espontânea pregressa por meio da ação demiúrgica do estado. Esta abordagem permite ao autor realizar um movimento mais ousado de interpretação, aproximando a experiência brasileira de "colonialismo interno" de um conjunto mais amplo de casos de colonização, notadamente os referidos na literatura antropológica sobre o orientalismo.

Ao aproximar, no capítulo 4, os elementos do repertório cultural e a produção dos documentos oficiais da FBC, o autor avança no desvendamento das mediaçôes entre a produção simbólica e as práticas estatais. O tema do colonialismo interno se materializa nas expressões e nas iniciativas de "criar colônias", de "colonizar" o Brasil Central, mobilizando políticas agrícolas e migratórias, embora nem sempre com sucesso. A representação da região como "colônia" ajustar-se-ia bem à sua posição em relação ao centro político-administrativo do país. O sertão era visto como um "espaço amorfo" que poderia ser integrado ao desenvolvimento nacional pela ação racionalizadora do estado em sua "utopia administrativa" e colonial. Ao mesmo tempo, uma engenharia social para civilizar os caboclos, fazendo deles agricultores proprietários em núcleos coloniais apoiados em estaçôes agrícolas de experimentação, centros de tecnologia, escolas rurais, conformando verdadeira "modelagem moral dos grupos subalternos". Como se sabe, a utopia administrativa da FBC encontraria resistência variada, seja nas elites locais, com as quais tinha que negociar a cessão de terras e outros problemas, seja nos próprios grupos subalternos. Do ponto de vista institucional, a precariedade da organização financeira e do ambiente econômico em que se desenhava tão grandioso projeto levaria a um progressivo asfixiamento da FBC, que terminaria incorporada à recém-criada Superintendência para o Desenvolvimento do Centro-Oeste (Sudeco) em 1967.

Ao desenvolver seu argumento apoiado na relação entre pensamento social e práticas estatais, João Maia contribui para uma compreensão sociológica e historicizada do processo de construção estatal, distante de noções essencializadas ou hiperinstitucionalistas. Ao mesmo tempo mostra como este é um estado que se constrói em movimento, fazendo da própria acumulação espacial uma de suas marcas. Estado criativo e demiúrgico no que diz respeito ao território, que precisa ser imaginado e recriado em função de projetos nacionais, característica que o autor atribui a processos de modernização periférica, nos quais o estado atuou como "criador do mundo social", inventando sujeitos e lugares. Modernização conduzida pelo alto, sem dúvida, o que implica doses elevadas de autoritarismo e coerção, mas que vista pelo ângulo do autor exigiria uma interpretação dialética. Se o ativismo estatal é movimento que parte do centro político-administrativo, houve para além da "utopia estatal" um movimento próprio da sociedade, bem representado pelos fluxos migratórios espontâneos, que po- 
dem inclusive inventar ou recriar produções simbólicas próprias, para além do "mundo administrado do capital” (p. 198). Daí a importância de abrir a caixa preta da formação territorial da autoridade no processo de modernização brasileira, na esperança de conectar esta "fronteira" a uma dimensão normativa democrática.

FELIPE MAIA GUIMARÃES DA SILVA é sociólogo e doutorando no programa de Sociologia do IESP-UERJ.

E-mail: 